\title{
Graves' disease associated with exophthalmos, cerebral ventricular dilatation and accelerated growth
}

Osamu Arisaka, Atsuto Hosaka, Hajime Arai, Sachi Fujiwara, Rieko Tadokoro, Keijiro Yabuta

Juntendo University School of Medicine, Tokyo, Japan:

Department of Pediatrics

O Arisaka

A Hosaka

S Fujiwara

R Tadokoro

K Yabuta

Department of

Neurosurgery

H Arai

Correspondence to: Dr O Arisaka, Department of Pediatrics, Juntendo University School of Medicine, 2-1-1 Hongo, Bunkyo-ku, Tokyo 113, Japan.

Accepted 23 September 1996

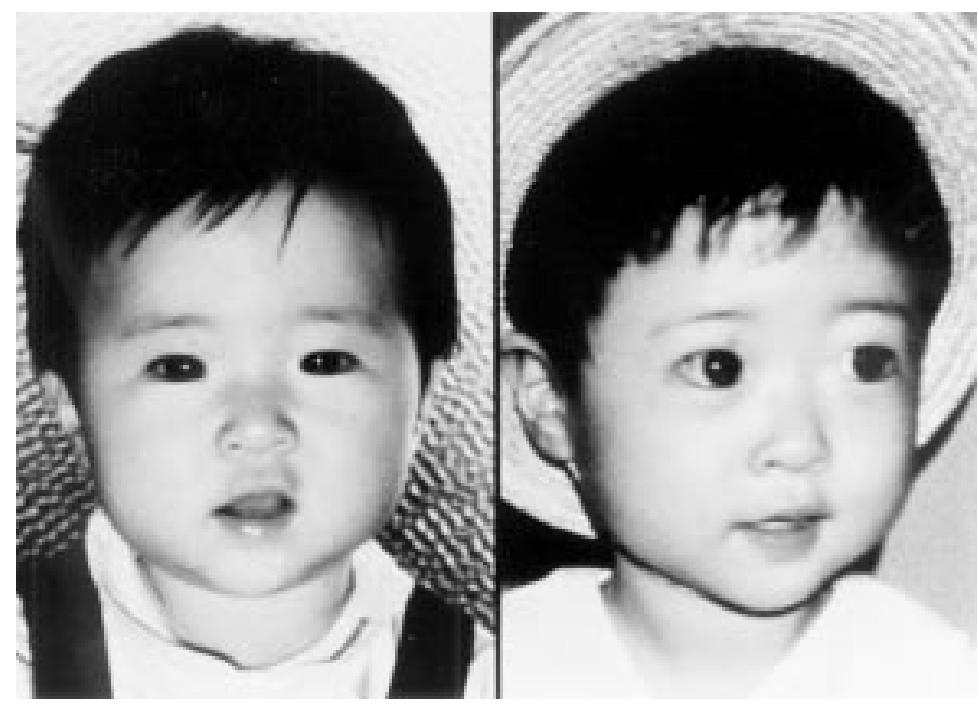

Figure 1 Signs of exophthalmos in the patient. Left, patient at 8 months showing no exophthalmos. Right, patient at 1.2 years when prominent eyes (mild exophthalmos) are evident.

\begin{abstract}
A report is presented of a girl with Graves' disease, which was diagnosed at the age of 1.7 years. The mother had no thyroid disease. The patient developed signs of hyperthyroidism shortly before her first birthday, and the most prominent manifestations were accelerated skeletal maturation and linear growth, and dilatation of the brain ventricles. The latter manifestation, which has not been reported previously, was reversible upon normalisation of thyroid function with antithyroid treatment for three years.

(Arch Dis Child 1997;76:62-64)
\end{abstract}

Keywords: Graves' disease; reversible ventriculomegaly; growth acceleration.

Hyperthyroidism during childhood is usually caused by Graves' disease. Apart from the transient neonatal cases that develop in infants born to mothers with active Graves' disease, the disease occurs infrequently in preschool children and rarely may begin in infancy. ${ }^{1}$

We describe the four year clinical course of a patient with Graves' disease that was diagnosed at 1.7 years of age, although the disease had probably developed in late infancy. There were typical clinical signs of hyperthyroidism, but

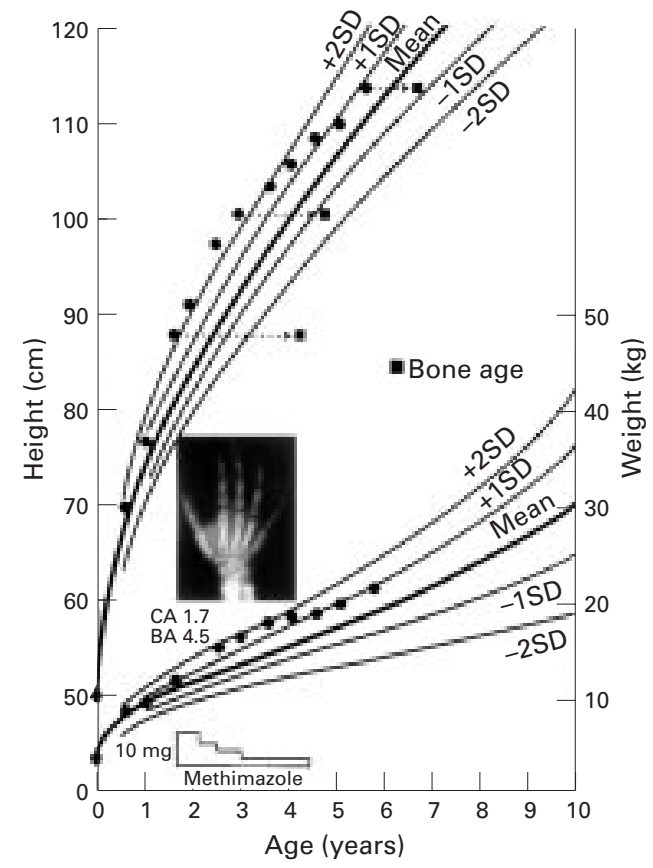

Figure 2 Patient's growth curves and serial measurements of bone age. Radiograph of hand shows the bone age (BA) at diagnosis $(C A=$ chronological age). Accelerated linear growth and advanced bone age became less remarkable after initiation of antithyroid treatment.

the patient's growth and development were most affected.

\section{Case report}

A girl aged 1.7 years was referred because of bilateral exophthalmos (fig 1). She had been born normally (weight $2980 \mathrm{~g}$ ) as the first child to a healthy mother. The family history did not suggest thyroid disease or other autoimmune diseases. The patient was $88.2(+2.5 \mathrm{SD}) \mathrm{cm}$ tall, with a body weight of $12 \mathrm{~kg}$ and a head circumference of $46.5(+0.2 \mathrm{SD}) \mathrm{cm}$. She presented with restlessness, sweating, mild thyromegaly, tachycardia (130/min), and a systolic murmur (Levine 3/6). She had upper eyelid retraction and infrequent blinking. The anterior fontanelle was closed, and there was no frontal bossing or craniosynostosis. She had increased deep tendon reflexes, and her optic fundi were normal.

Further questioning revealed that these signs had developed shortly before 1 year of age. However, her milestones of motor and mental development up to the time of presentation had been normal except for linear growth accelera- 
Table 1 Laboratory data of the patient at admission

\begin{tabular}{lll}
\hline & Value & Normal for age \\
\hline Endocrinological data & & \\
Thyroxine (nmol/1) & 463 & $90-180$ \\
Triiodothyronine (nmol/l) & 7.9 & $1.3-3.8$ \\
Thyroid stimulating hormone (mU/l) & $<0.05$ & $2-8$ \\
TBII (\%) & 52.2 & $<10$ \\
Biological activity of thyroid stimulating hormone antibodies & 500 & $<145$ \\
$(\%)^{\star}$ & & \\
Antimicrosomal antibody & $<1: 10$ & $<1: 10$ \\
Insulin-like growth factor I (U/1) & 0.78 & $0.3-1.0$ \\
Oestradiol (pmol/1) & $<30$ & $<30$ \\
Osteocalcin (nmol/ml) & 10.5 & $1.6-3.2$ \\
Biochemical data & & \\
Total cholesterol (mmol/l) & 2.9 & $2.7-4.5$ \\
Creatine kinase (U/l) & 125 & $50-150$ \\
Alanine aminotransferase (U/1) & 28 & $5-35$ \\
Alkaline phosphatase (KAU/l) & 33 & $15-25$ \\
Urinary calcium/creatinine ratio & 0.9 & $<0.15$ \\
\hline
\end{tabular}

${ }^{\star}$ Cyclic AMP generation by rat thyroid cell line with patient's serum. ${ }^{4}$

tion with advanced skeletal development ( 4.5 years by TW2 method for Japanese children ${ }^{3}$ ) (fig 2). Also, a photograph taken at the age of 8 months revealed no exophthalmos (fig 1).

Thyroid function tests including immunological tests and biochemical tests are shown in table 1 . The mother was euthyroid and had no detectable antithyroid antibodies including antimicrosomal antibody and thyrotrophin binding inhibitory immunoglobulins (TBII). Cardiomegaly (cardiothoracic ratio $60 \%$ ) was recognised in a chest $x$ ray film, and mitral valve regurgitation was detected by colour Doppler echocardiography. Brain computed tomography had shown dilatation of the ventricular system (fig 3). This scan had been carried out at the referred hospital to rule out retro-orbital tumours.

A diagnosis of Graves' disease was made and treatment was started with antithyroid drug (methimazole $10 \mathrm{mg}$ daily) and a $\beta$-adrenergic blocker (propranolol $5 \mathrm{mg}$ daily). Thyroid function became normal in several months. Propranolol was then withdrawn and the dose of methimazole was reduced (5-2.5 mg), but maintained thereafter. The systolic heart murmur and exophthalmos (fig 1) remained for two to three years and ventricular dilatation regressed over a four year period (fig 3 ).

Antithyroid treatment was stopped at the age of 4.5 years, when thyroid function (thyroxine $93.9 \mathrm{nmol} / \mathrm{l}$; triiodothyronine $2.15 \mathrm{nmol} / \mathrm{l}$; thyroid stimulating hormone $2.27 \mathrm{mU} / 1$; TBII $2.9 \%$ ) and the result of a triiodothyronine suppression test appeared normal. During the treatment, there were no complications.

On review at 5 years of age, the patient was within the normal ranges for social, motor, and communicative development. Her growth curve with skeletal ages are shown in fig 2 . At present, sexual development is Tanner stage I.

\section{Discussion}

Occasionally, neonatal hyperthyroidism does not remit and persists into childhood. Such patients may have a family history of hyperthyroidism, although circulating thyroid antibodies are absent. ${ }^{256}$ It has recently been established that children with this disorder have a mutation of the thyroid stimulating hormone

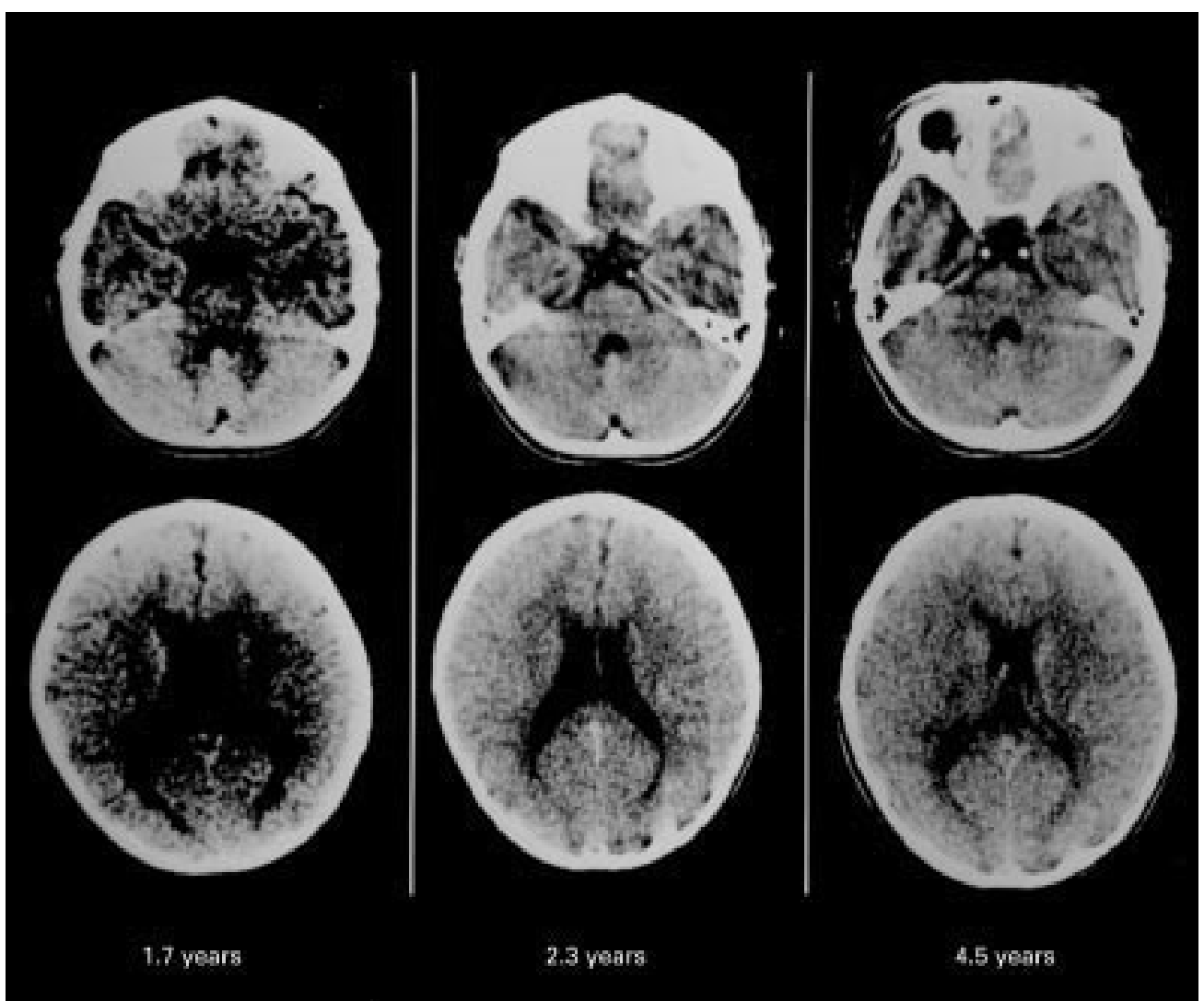

Figure 3 Serial examinations by brain computed tomography. Dilated lateral ventricles (bottom) and fourth ventricles (top) regressed after antithyroid treatment. Left: 1.7 years (at diagnosis of Graves' disease); centre: 2.3 years; right: 4.5 years. 
receptor gene. ${ }^{7}$ In the present patient, the autoimmune pathogenetic mechanism of adult Graves' disease was operating, because circulating thyroid stimulating hormone antibody was evident at the time of diagnosis and its activity decreased as the disease ameliorated.

As Graves' disease progresses insidiously, it is difficult to know when the hyperthyroidism in the present patient developed. It may not have occurred until mid-infancy, because exophthalmos, clinical signs of hyperthyroidism, and growth acceleration had not been evident until then. Furthermore, skull abnormalities, such as frontal bossing, craniosynostosis, and microcephalus, which are evidence of abnormal membranous bone maturation due to the early effect of thyroid hormone, ${ }^{8-10}$ were not recognised in the present case. Therefore we suspect that the disease developed at a later stage of infancy.

In our patient, there were various typical manifestations of hyperthyroidism, some of which are usually seen in older patients. The most prominent manifestation was accelerated skeletal maturation and growth, although these phenomena have been reported to occur commonly in young children with Graves' disease. ${ }^{12}$ The raised serum osteocalcin level and the increased urinary calcium/creatinine ratio would have indicated a bone metabolic status representative of increased bone turnover due to excess thyroid hormone. ${ }^{11}$

The ventriculomegaly in the present case was an unexpected finding. This feature has been documented in only one report of twins with congenital hyperthyroidism associated with ventriculomegaly and cerebral atrophy revealed by computed tomography; however, these abnormalities associated with mental delay were thought to be caused by brain maldevelopment in utero due to maternal hyperthyroidism. ${ }^{12}$ Pseudotumour cerebri (benign intracranial hypertension) occurs in association with a variety of endocrine and metabolic disorders including hypothroidism and hyperthyroidism, but cranial computed tomography usually shows normal sized ventricles, and funduscopic examination shows papilloedema on. ${ }^{13-15}$ The ventriculomegaly in our patient was reversible with normalisation of thyroid function. Alterations in cerebrospinal fluid absorption and/or production, or abnormality of cerebral blood flow due to hyperthyroidism may have been responsible for this brain manifestation. Fortunately, this involvement did not appear to affect the psychomotor development of the patient.

The persistent form of Graves' disease which develops in infancy, as described here, is very rare, but early recognition and antithyroid treatment are critical because a delay in the diagnosis of such young patients can have a marked effect on growth and development.

This work was presented at the 29th Annual Meeting of the Japanese Society for Pediatric Endocrinology, Okayama, Japan, November 1995.

1 Delange F, Fisher DA. The thyroid. In: Brook CGD, ed. Clinical paediatric endocrinology. 3rd Ed. Oxford: Blackwell Science, 1995:397-433.

2 Hayles AB, Zimmerman D. Graves' disease in childhood. In: Ingbar SH, Braverman LE, eds. Werner's the thyroid. 5th Ed. Philadelphia: J B Lippincott, 1986:1412-28.

3 Murata M. Japanese specific bone age standard on the TW2. Clin Pediatr Endocrinol 1993;3:suppl 3:35-41.

4 Arisaka $\mathrm{O}$, Arisaka $M$, Nakayama Y, et al. Thyrotropin bindArisaka O, Arisaka M, Nakayama Y, et al. Thyrotropin bind-
ing inhibitor immunoglobulin. Am $\mathcal{F}$ Dis Child 1986;140: ing inhibitor

5 Hollingsworth DR, Mabry CC. Congenital Graves' disease: four familial cases with long-term follow-up and perspective. Am $\mathcal{F}$ Dis Child 1976;130:148-55.

6 Fisher DA. Pathogenesis and therapy of neonatal Graves' disease. Am $\mathcal{F}$ Dis Child 1976;130:133-4.

7 Shenker A. G protein-coupled receptor structure and function: the impact of disease-causing mutations. Baillieres Clin Endocrinol Metab 1995;9:427-51.

8 Robinson DC, Hall R, Munro DS. Graves' disease, an unusual complication: raised intracranial pressure due to premature fusion of skull sutures. Arch Dis Child 1969;44: 252-7.

9 Daneman D, Howard NJ. Neonatal thyrotoxicosis: intellectual impairment and craniosynostosis in later years. F Pediatr 1980;97:257-9.

10 Cove DH, Johnston P. Fetal hyperthyroidism: experience of treatment in four siblings. Lancet 1985;i:430-2.

11 Garnero P, Vassy V, Bertholin A, Riou JP, Delmas PD. Garnero P, Vassy V, Bertholin A, Riou JP, Delmas PD.
Markers of bone turnover in hyperthyroidism and the effects of treatment. F Clin Endocrinol Metab 1994;78:9559.

12 Kopelman AE. Delayed cerebral development in twins with congenital hyperthyroidism. Am f Dis Child 1983;137:8425.

3 Menkes JH, Hurvitz CGH, Mcdiarmid SV, Williams RG. Neurologic manifestations of systemic disease. In: Pine JW, ed. Textbook of child neurology (Menkes). 5th Ed. Baltimore: Williams and Wilkins, 1995:873-923.

14 Dickman MS, Somasundaram M, Brzozowski L. Pseudotumor cerebri and hyperthyroidism. NY State $f \mathrm{Med}$ 1980;80:1118-20.

15 Huseman CA, Torkelson RD. Pseudotumor cerebri following treatment of hypothalamic and primary hypothying treatment of hypothalamic and pr
roidism. Am f Dis Child 1984;138:927-31. 